\title{
The Disability Models in the Perspective of Parents, Teachers, and Special Needs Educators: A Qualitative Data Analysis
}

\author{
Stefano Federici*, Fabio Meloni, Alba Brogioni and Alessandra Lo Presti
}

Piazza Ermini, 1 - 06123 Perugia, Italy, Department of Human and Educational Sciences, University of Perugia, Italy

\begin{abstract}
Representations of disability shaping the opinions, attitudes, and behaviour of 90 participants (teachers, parents, and special needs educators) are investigated in order to better evaluate the spread of the biopsychosocial model proposed by the ICF. The quasi-experimental purpose was investigated through both qualitative analyses and by quantitative analyses. The results demonstrate a richness of perspectives on disability much broader than the medical, social, and biopsychosocial ones. The limited diffusion of the biopsychosocial model among parents shows the lack of an 'open view' towards personal empowerment, social growth, and improvement of the quality of life. This suggests a priority: The need to further involve parents in the educational actions, in order to promote an effective management of personal and environmental resources to better face the disability of their own children. In such a way it would be possible to develop and promote a new 'culture of diversities'.
\end{abstract}

Keywords: Models of disability, parental attitudes, ICF, biopsychosocial model, Computer Assisted Qualitative Data Analysis Software, Atlas.ti, special needs educators.

\section{INTRODUCTION}

\section{On Disability Models}

When Peggy Quinn, in her Understanding disability: A lifespan approach [1], recalled the relevance of offering to the parents of children with disabilities an early information about their children's development (making them understand how their child will grow up physically, socially, and cognitively and how to help and encourage them to obtain the maximum progress), attention was once again focused on how the communicative stimulus affects that very diachronic communicative process - which always concerns our being either parents or children, doctors or patients, normal or disabled. This process (expressed in those real situations that are not always considered possible by the same parents), in which the meaning of the relationship with that child whose diversity astounds us, is to be found. If this sense arises from the evaluation of a disability which follows a typical development model, such as Piaget's or Eriksons', it will be certainly focused on deficit and on aspects that will make the disabled children not able to fit into the expected development standards [2].

Therefore, the disability models are categorical representations in which the social relations are understood, built, and given; not only the frames where everyone finds their own identity, but also where it generates other identities in that complex system of attribution that defines us:

\begin{abstract}
'Society establishes the means of categorizing persons and the complement of attributes felt to be ordinary and natural for members of each of these categories' [3].
\end{abstract}

*Address correspondence to this author at the Piazza Ermini, 1 - 06123 Perugia, Italy, Department of Human and Educational Sciences, University of Perugia, Italy; E-mail: stefano.federici@unipg.it

\section{Disability Models from a Psychological Cognitive- Constructivist Perspective}

From our psychological perspective, we believe that the use of disability models is justified not so much by their function of favouring the understanding of disability, but by the nature itself of the functioning of the human mind. In the mind, reality is the result of interpretative/reconstructive information processing that turns a real entity into an object observed and experienced by a subject [4]. The fact that this construction of reality is not arbitrary is confirmed by the survival of the human race which, in its constant evolution, demonstrates a surprising ability of adaptation to the environment.

Therefore, following our perspective, disability models should not only be considered as useful access tools to deal theoretically and practically with a too complex reality, but as the possibility itself to access that reality called disability. That disability is should then brought back to etiopathological causes, to social structures, to cultural discrimination, to divine punishment, to chakra disharmony, pertains to the diversity of the models that, we reassert, are not a simple interpretation of a malfunctioning, but the means of experiencing it.

\section{Purpose}

In this work we present the results of a qualitative investigation about the vision of disability of parents with disabled and non disabled children, non-specialized and specialized teachers ${ }^{1}$, professional special needs educators, and so-

\footnotetext{
${ }^{1}$ As non-specialized teacher we intend a teacher qualified for teaching his/her own discipline (i.e., maths, history, literature, etc.) but not specialized to support students with special needs. On the other hand, a specialized teacher is a teacher not only qualified to teach a discipline, but also specialized to support students with special needs. In fact, in accordance with Italian law no.104, February, $5^{\text {th }}, 1992$, students with special needs and disabili-
} 
cial-health workers. Two reasons pushed us to develop this investigation: first, to study more deeply the relationship among disability, adaptation, socialization, and development and second, to verify the spread of the biopsychosocial model proposed by the International Classification of Functioning, Disability, and Health $(\mathrm{ICF})^{2}$ [5].

In order to investigate which disability models inform the social and educational relations of a disabled student we observed the 'communicative stimuli' that affect development, even beyond the parental relationship. Moreover, revealing the perspective of parents, teachers, and educators on disability could offer precious and rare information about the spread of concepts of the new ICF classification and of the biopsychosocial model among different categories of people who, even if sharing the school environment, come from different conditions and educations where disability is concerned.

Italy, since the 1970s, has been featured an excellent legislative corpus on school integration, social inclusion, equal opportunities, and accessibility to information technologies, which have long since integrated some of the fundamental ICF concepts, such as the inclusion of environmental factors among the dimensions influencing the construct of disability. Nevertheless, this fact most probably makes the new features of ICF less evident, making its popular acknowledgement paradoxically more difficult. Moreover, the medical and legal evaluation system at the base of our social security system, based on 'invalidity scores', even if very far from the perspective of the biopsychosocial model, still constitutes a huge obstacle for the innovation proposed by ICF. Introducing a vision of disability and invalidity not reducible to the application of a list of physical disablements would call for an enormous socio-structural change of the social security system that would touch corporate interests and privileges, so resistant to political changes.

\section{International and Scientific-Literary Production on Teachers' and Parents' Vision of Disability}

From a research on the main databases of international indexed scientific publications (Cambridge Scientific Abstracts: social sciences area), no Italian studies were found dealing with the view on disability featured by teachers, parents, or special needs educators.

Also at an international level, literary material concerning this matter is scarce; only four international journals give space to this topic, for a total of six articles: two on Disability and Society $[9,10]$, two on the Journal of Contemporary Ethnography $[11,12]$, one on the Journal of Medical Humanities [13] and one on the British Journal of Special Education [14]. All these studies are mainly about parents' per-

ties have the right - and in compulsory school curriculum, the duty - to be integrated in the mainstream school system. As a consequence, each school communicates to the local education office the number of students with special needs who necessitates of a specialized teacher who may work in classrooms which the special needs students are enrolled in, along with nonspecialized teachers.

${ }^{2}$ For a review of the literature produced in the three years following the ICF approval, see Bruyère, Van Looy, and Peterson [6]. For a close analysis of the revision path that led from ICIDH in 1980 to current ICF, we suggest the excellent work by Bickenbach, Chatterji, Badley, and Üstün [7]. Lastly, for a critical work about ICF's biopsychosocial model and about models of health prevention, see Federici and Olivetti Belardinelli [8]. spectives, except the work by Adams, Swain and Clark that is dedicated to the teachers' point of view about the meaning of 'specialness' (referred to English 'special' schools) in theory and practice.

All authors adopted the medical and social models as criteria to qualitatively evaluate and interpret their data. Moreover, no one of them, no exceptions made, makes any reference to the biopsychosocial model. Even when researchers looked for alternative models to the medical and social ones, - Jenks' 'middle' model [11], Brett's alliance one [10], Kelly's inter-subjective and inter-corporeal one [12], the social position of the medical model revised by Ong-Dean [13] - or when they called for the need of education projects not favouring one model to the disadvantage of the other, encouraging the integration of the values of both, as Asprey and Nash did [14] along with Adams, Swain, and Clark [9], no mention was made of the biopsychosocial model or the ICF.

In the following paragraphs we will present and discuss the data collected during an investigation on the vision of disability featured by parents, teachers, social- health workers, and special needs educators, from four Italian regions (Lazio, Molise, Umbria, and Apulia), analysed with a qualitative coding and textual interpretation, as well as a quantitative analysis, both assisted by the Atlas.ti software.

\section{METHOD}

\section{Aims of Descriptive Research and Quasi-Experimental ${ }^{3}$ Hypotheses}

The general purpose of this study is to explore which representations of disability orient the opinions, attitudes, and behaviour of people who spend, for affective or professional reasons, large amounts of their time with a disabled person on a daily basis. The fulfilment of this research purpose is based on the assumption that it is possible to infer inductively, from these representations, the disability models that inform the affective, social, and educational relations of a disabled student.

The quasi-experimental aim was investigated with qualitative analyses, text coding and interpretation, and quantitative software-assisted data analyses. The latter were carried out, with explorative purposes, with only two statistical hypotheses:

1. In the quantitative analyses, the disability model attributed to each role homogeneous group depends on the highest number of expressions coded as consistent with that specific model;

2. The disability model significantly prevailing in each role-homogeneous group correlates with the participants' modalities of expression of their personal experience.

\footnotetext{
${ }^{3}$ Our research is a 'quasi-experiment' because the participants have not been randomly assigned to conditions (social roles) but, instead, are assigned to particular conditions on the basis of some mainly inherent characteristic (the fact to be parents, teachers, social-health workers, or special needs educators) [15]. In any case, we also use 'experiment/al' (e.g., experimental stage) in order to simplify the text exposition, but intending it as a quasiexperiment/al one.
} 


\section{Participants}

The enrolment of the participants - non-specialized and specialized teachers, parents of disabled and non disabled students, social-health workers, and special needs educators was carried out exclusively in schools and local educational agencies, or in local associations and organizations dedicated to the care, assistance, and education of disabled people. As far as the specialized teachers is concerned, after obtained the qualification teaching diploma a teacher must attend a post-graduate semester which envisages training in a state school with special needs students, who are integrated in classrooms along with normal students. The social work and special needs educator university courses also envisage a training which the social worker- and educator-to-be serve either in public or in private structures under the supervision of a regular worker.

In each group of participants, sharing the school environment but coming from different conditions, experiences, and education about disability, we investigated the general perspective on disability, in order to verify how widely spread the concepts of ICF's new classification are, as well as the biopsychosocial model conceptually compatible with this classification.

The participants in the groups were invited on the basis of only one specific educational role, even where they had more than one. Therefore, each participant knew that he/she was participating in only one of the following groups, divided by role: parents of disabled children, parents of non disabled children, non-specialized teachers, specialized teachers, professional special needs educators, and socialhealth workers.

90 participants (69 F; $21 \mathrm{M}$; mean age: $47 \mathrm{yrs)} \mathrm{were} \mathrm{in-}$ volved in the study (Table 1), divided in groups as follows: 30 (23 F, $7 \mathrm{M}$ ) parents of disabled students, 7 (6 F, $1 \mathrm{M}$ ) parents of non disabled students, 20 (18 F, $2 \mathrm{M})$ non-specialized teachers, $14(11 \mathrm{~F}, 3 \mathrm{M})$ specialized teachers, $6(3 \mathrm{~F}, 3 \mathrm{M})$ professional special needs educators, $13(8 \mathrm{~F}, 5 \mathrm{M})$ socialhealth workers. The subjects were recruited from several Italian State Education Institutes (Comprehensive Institute in Sant'Elia a Pianisi - CB); State Elementary School Stella Polare - RM; Social-Psycho-Pedagogical Lyceum, Cisternino BR; Elementary School of Selci, San Giustino - PG), and from several Assistance Associations, relevant at regional or national level (Unione Italiana Ciechi, Associazione Italiana Sclerosi Multipla, Associazione Perlha, Fondazione Italiana Verso il futuro, Parent Project Onlus, Centro Arcobaleno, Cooperativa Fiore Verde), located in four Italian regions: Umbria, Lazio, Molise, and Apulia.

\section{Research Tools}

The focus group, being at the same time an observation technique and a type of interview, was chosen as the main tool to gather the data relevant for the research aims. Several authors [15-21] highlight the appropriateness of the focus group as an investigation tool when the researcher is concerned about exploring complex ideas, connected with personality dynamics, such as opinions, beliefs, emotions, and motivations.

Along with the indications of Krueger [22], the focus group moderation, in this research, was pre-defined with the construction, in the pre-experimental stage, of a Moderation Grid, including a topic guide implemented in a questioning route (Table 2 ).

The topic guide identifies the thematic units to be explored during the focus group, with a hierarchical sequence, organized according to the 'superficial/in depth' polarity and it also allows the temporal subdivision of the discussion in four primary stages: introduction, interpersonal facilitation, deep enquiry, and conclusion.

The questioning route is the articulation of the topic guide in a carefully predefined sequence of questions, mostly 'open', eventually including 'gradation' exercises. The latter are precious tools to reveal the cultural models that implicitly guide people in their daily life.

\section{Research Stages}

The research was developed in two consecutive stages: pre-experimental and experimental.

Pre-experimental stage - In this stage we defined the goals of the research, along with the tools of investigation and analysis. In order to precisely assess the foremost disability model in each group of subjects, we arranged 17 focus groups (Table 1), homogeneous in social role and residence of the participants.

Table 1. Number of Focus Groups and Participants, Divided by Region and Role

\begin{tabular}{|c|c|c|c|c|c|c|c|c|c|c|}
\hline Roles & FG* & $\mathbf{N P} * *$ & FG* & $\mathbf{N P} * *$ & FG* & $\mathbf{N P} * *$ & FG* & $\mathbf{N P} * *$ & FG* & $\mathbf{N P} * *$ \\
\hline Parents of disabled students & 4 & 21 & 1 & 5 & & & 1 & 4 & 6 & 30 \\
\hline Parents of non disabled students & 1 & 7 & & & & & & & 1 & 7 \\
\hline Specialized teachers & 1 & 3 & & & 1 & 6 & 1 & 5 & 3 & 14 \\
\hline Special needs educators & & & & & 1 & 6 & & & 1 & 6 \\
\hline Social-health workers & & & 1 & 5 & & & 2 & 8 & 3 & 13 \\
\hline Total by Region & 7 & 37 & 2 & 10 & 3 & 19 & 5 & 24 & 17 & 90 \\
\hline
\end{tabular}

*Number of Focus groups. **Number of participants. 
Table 2. The Moderation Grid

\begin{tabular}{|l|l|}
\hline \multicolumn{1}{|c|}{ Topic Guide } & \multicolumn{1}{c|}{ Questioning Route } \\
\hline \hline $\begin{array}{l}\text { Personal opinions on the con- } \\
\text { cept of disability }\end{array}$ & What is disability? \\
\hline Universal model & Did you ever experience disability conditions? \\
\hline $\begin{array}{l}\text { Adhesion to the medical, social, } \\
\text { or biopsychosocial models }\end{array}$ & $\begin{array}{l}\text { Gradation exercise } \\
\text { Did you experienced disability as: } \\
\text { - a personal condition } \\
\text { - a condition created by the physical/social environment } \\
\text { - a condition created by personal characteristics and environmental characteristics }\end{array}$ \\
\hline Ability and Disability & When you perceived your disability, what relation did you have with your abilities? They were all eliminated? \\
\hline Functioning & $\begin{array}{l}\text { Presentation of Rosanna Benzi's story and narration concerning of Vineyard Island's deaf community } \\
\text { Is it possible to perceive oneself as well functioning, even possessing disabilities? }\end{array}$ \\
\hline Types of intervention & $\begin{array}{l}\text { How we should intervene to improve the conditions of disability? } \\
\text { On this basis, would you be willing to change invalidity scores? }\end{array}$ \\
\hline
\end{tabular}

In this stage were also specified both the thematic units to be discussed (topic guide) and the articulation and sequence of the questions to be addressed to the participants (questioning route). The ICF and the biopsychosocial model were the reference points to identify the topics and the questions. More specifically, the definition of the questioning route, when the thematic units of the topic guide were specified, was oriented to reveal, rather than the opinions 'about disability', the direct experiences 'of disability' lived by the participants in first person.

We believed, for instance, that the diffusion of the universal disability model - characterizing the revision process that led from International Classification of Impairments, Disabilities, and Handicaps (ICIDH) [23] to ICF [7] - was better observable by posing the question: 'Did you ever experience disability conditions?', rather than 'Do you think that everybody has experienced a disability condition at least once in his/her life?'.

During the phase of setting up the questions, we also decided to include concepts such as disablement, limitation, disadvantage, handicap, and all the other expressions commonly used with similar meaning, within the single term 'disability' as an umbrella term [5] to reduce possible terminological misunderstanding.

The choice of the tools for the analysis largely depended on the aim of the study itself, in addition to the type of data we gathered. In the manual text analysis a top-down procedure was used: starting from the models of disability as they have been described in the literature, the phrases of the focus group participants, which were more adherent to a concept of a disability model, were codified as belonging to that model. Differently, in the analysis assisted by Atlas.ti software a bottomup procedure was carried out. In that case, the assessment of the underlying disability models, starting from the coding of the main representations which emerges from the focus groups, is a consistent operation to the approach supported by the scientific foundations of the Grounded Theory [24]. The programme Atlas.ti was designed within the frame of the Computer Assisted Qualitative Data Analysis Software (CAQDAS) Networking Project [25-27] at the beginning of the 1990s: software conceived to analyse data in a qualitative approach, by means of interpretation, compatible with the theoretical basis of the Grounded Theory [28].

Experimental stage - In this stage we carried out 17 focus groups in four Italian regions (Table 1). All the focus groups conversations were audio recorded for a total of approximately 17 hours. The conversations were then transcribed, analysed, and interpreted, following methods and procedures described in the following paragraph.

\section{QUALITATIVE DATA ANALYSIS PROCEDURES AND RESULTS}

\section{Manual Text Analysis Procedures}

The purpose of the manual analysis of the text was to verify the perspectives on disability according to the different educational roles: parents of disabled students, parents of non disabled students, non-specialized teachers, specialized teachers, professional special needs educators, and socialhealth workers.

Firstly, all the 17 hours of audio recordings from the focus groups were transcribed. Then, the texts were carefully read and indexed, namely, the most significant verbal expressions were identified and a code/index was assigned to each one. The significant of the verbal expressions was consistently evaluated, among the above mentioned expressions, as regards the most adherent to one of the three disability models (medical, social, and biopsychosocial), as they have been described in the literature. Therefore, the code categorized the sentences according to the medical, or social, or biopsychosocial disability model. Overall, 37 codes were identified in this phase: 17 in reference to the social model, 8 to the medical one, and 12 to the biopsychosocial one. For example:

- The code/index 'disability as condition of diversity created by the society', which we referenced to the social model, was assigned to verbal expressions such as:

'...I think that the paradox about the people with a more or less severe handicap is not about themselves, but about us around them, they don't know what we are asking for, the problem is us, not them...'. 
Indeed, according to the social model, the disability has nothing to do with the body; rather, it is a consequence of environmental and cultural barriers [30].

- The code/index 'disability and ability in a continuum' that we referenced to the biopsychosocial model, was assigned to expressions such as:

'...but there is nobody completely able or completely disable...'.

Indeed, the biopsychosocial model conceives abilitydisability as a continuum, so that the complete absence of ability is a limiting case of theoretic interest only: [7].

- The code/index 'disability as physical condition', referenced to the medical model, was assigned to statements such as:

'...there is a physical disability, it's a reality...'

The medical model, instead, views disability as a linear and direct consequence of a body impairment $[5, \S 5.2 ; 23]$.

After the manual coding, we calculated the more frequent indexes in each focus group, and we assigned to each educational role the prevailing disability model.

In a qualitative analysis, a less frequency does not necessarily mean less relevance. At all events, since the goal of our study is not a survey on the most relevant concepts about disability, but it is about the expression modalities of thought on disability, the frequency has been considered a clue of relevance.

\section{Manual Text Analysis Results}

The text analysis manually performed highlighted different perspectives on disability, according to the educational role held by each group of participants. Table 3 shows the evaluations of the disability models, in each rolehomogeneous group.

In every role-homogeneous group, except for the special needs educators' one, the social model appeared as the prevailing one. However, as showed in Table 3, in more than one group the evaluation was not so univocal.

Among the parents of disabled and the non-specialized teachers, the social disability model was evaluated as the foremost, since the codes/indexes relative to that model were the most frequent ones in almost all the focus groups; only in a group of non-specialized teachers in Molise, the biopsy- chosocial model was indicated as the more represented.

It was not possible to attribute a single model to the other groups. Among the parents of non disabled children, even though the social model seemed to prevail, the presence of the medical and the biopsychosocial model were detected. In particular, the medical model was especially used for the 'tragic' aspect of disability, and associated in negative terms to the condition of the disabled, such as 'problema' (problem) and 'croce' (a cross to bear). Among the specialized teachers and the social-health workers emerged an oscillation between the social and the biopsychosocial models. This would confirm what is reported in literature about the appearance of a so-called transitional model that would account for aspects of both models [10,11].

\section{Procedure of the Analysis Assisted by Atlas.ti Software}

The text analysis was performed also with a computerized procedure, using the Atlas.ti software for qualitative analyses.

The first operative phase in Atlas.ti work was the creation of the Hermeneutic Unit, which includes different elements to be analysed (texts, audio and video recordings) - in our case, only texts - that, once inputted, form the so-called Primary Documents.

After entering the Primary Documents in the Hermeneutic Unit we moved on to the data coding, with the categorization process of the Grounded theory [31], divided in the following coding phases: 1 - open coding (breaking down, examining, comparing, conceptualizing, and categorizing data often, in terms of properties and dimensions [24]; 2 - selective coding (that is the process of choosing one category to be the core category, and relating all other categories to that category); 3 comparison and categorization; 4 - re-reading and modifying.

In the 'open coding' phase, the significant text fragments about disability (quotations) were identified and a descriptive code was assigned to each one. For instance, the following definition of disability expressed by a parent in a focus group: '...everything that differentiates someone or something from... from being able or not being able to do it... or having difficulties in doing it...', was coded as 'disability seen as limitation of ability'.

This coding allowed us to group the contents of the texts into conceptual cores, summarizing their information load. Unlike the manual procedure, where the significant parts were labelled with codes immediately related to the three disability models (top-down procedure), in the coding with

Table 3. Evaluation of Disability Models Prevailing in the Groups, As Resulting from the Manual Text Analysis. The Number Points Out the Frequency of the Three Disability Models Codes

\begin{tabular}{|l|c|c|c|}
\hline \multicolumn{1}{|c|}{ Roles } & Medical Model & Social Model & Biopsychosocial Model \\
\hline \hline Parents of disabled students & 63 & $215^{*}$ & 80 \\
\hline Parents of non disabled students & 18 & $23^{*}$ & 15 \\
\hline Non-specialized teachers & 45 & $71^{*}$ & 43 \\
\hline Specialized teachers & 22 & $60^{*}$ & $24^{* *}$ \\
\hline Special needs educators & 4 & 12 & $20^{*}$ \\
\hline Social-health workers & 28 & $55^{*}$ & $51^{* *}$ \\
\hline *Model prevalent describing of the opinions for the majority of the group **Model spread in the group even if not descriptive of the opinions of the majority
\end{tabular}

*Model prevalent describing of the opinions for the majority of the group. **Model spread in the group even if not descriptive of the opinions of the majority. 
Atlas.ti the codes were assigned by letting the data take the lead. By following this procedure, we were able to verify the correspondences of these codes to the theoretical aspects of each model. 36 codes were created from this analysis, among which:

- enabling social environment ('I think that disabled must be included not stigmatized');

- disabling social environment ('I am talking about a disabled child with serious emotional and behavioural problems, who lives expecting that other people which are his/her personal physical and non physical needs, because he/she is not understood...');

○ enabling social-educational environment ('if everybody plays football and someone else does not, it's unfair because everybody must have chance to play... and vice versa; if everybody uses a pen and someone else plasticine, why? Everybody must have the chance to use plasticine and play football...');

- disabling social-educational environment ('It often happens that classmates pick on disabled students');

environmental barriers ('There were lots of barriers and problems, it was impossible to get bus...use the underground system... you cannot use a pushchair...because not all underground stations have a lift');

diversity of the disable ('They are children that give you something, they encourage you and know having not something less than others but something different');

○

disability as a subjective condition ('An insecure individual feels always disability in person, well, at least, I always feel that');

O

disability not as absence of ability ('I think that if someone is not able to communicate in words he/she will try to do it in a different way...it's the same thing when you don't see...you'll try to touch'); etc.

In a subsequent phase, the 36 codes were joined in 'families' representing theoretical dimensions containing the information of empirical indicators (in our case, the codes). The unification into families was carried out at different levels:

1. Of the 36 original codes, 21 , sharing similar conceptual cores, were put together in 3 code families: the 'environment', the 'disability as personal condition', the 'continuum between ability and disability';

2. All the 36 codes were unified according to established theoretical dimensions, in relation to 3 disability models: medical model, social model, and biopsychosocial model;

3. All the 36 codes were categorized in 5 dimensions related to personal experience: opinions, attitudes, behaviours, myths/stereotypes for each focus group, and emotions (anger, anguish, sadness, disgust, joy) for only 6 focus groups (one for each educational role).

\section{Results of the Qualitative Analysis Assisted by Atlas.ti}

The text analysis carried out with the computerized process partially confirmed the results emerged from manual indexing, showing some more nuances within and among the groups.

The social model is spread in all the role-homogeneous groups, except for the specialized teachers. However, only the parents of disabled students and the non-specialized teachers seem to claim decisively their adhesion to the social model, because of the small occurrence of codes related to other models. The parents of non disabled students oscillate between the social and the medical models, confirming what came out from the manual analysis. A result in contrast with the outcome of the manual procedure is the one concerning the special needs educators, seeming to oscillate between the social and biopsychosocial models, hence not showing a preference for the latter.

Lastly, the groups of specialized teachers and socialhealth workers call for a more articulated interpretation. Among the social-health workers, the social model is the foremost, despite the presence of several assumptions relative to the biopsychosocial model. Among the specialized teachers an oscillation among all the three disability models emerges. The medical model, which in the preceding manual analysis seemed to be maintained only by a group of nonspecialized teachers from the Molise region and, partially, by the parents of non disabled students, appeared also among the specialized teachers and the social-health workers.

The biopsychosocial model does not prevail in any group, but is more present among the social-health workers and the special needs educators, where it coexists with the social model and, rarely, with the medical one.

Thus, the quantitative analysis assisted by Atlas.ti seems to confirm the appearance of a transitional model, which largely features elements coming from the social and the biopsychosocial models and, in a lesser way, elements coming from the medical model. Moreover, the transitional model seems to spread only among the special needs educators and the social-health workers. The latter, in fact, seem to have a perception of disability closer to the biopsychosocial model, compared to the non-specialized teachers who highlight the need for a direct intervention on the context. The social-health workers succeed in not idealizing disability, by blaming only the environment, but, on the contrary, bear well in mind that the causes have to be tracked down in the interaction between personal and environmental conditions. The non-specialized teachers, on the conceptual level, believe that disability is a condition of the person, caused by deficit, by disablements of various types, and believe that the definition of pathology depends on external parameters chosen by following models that could differ according to social and cultural environment. On the operative level, they feel that the true disability that 'their students' face is born through the comparison with the other students and with an environment not devised to fit everyone's needs. The parents of disabled students are those showing the stronger adhesion to the social model. In their focus groups there is a recurrence of the emphasis on the key-role of the environment in 
discriminating and excluding the disabled, but also the criticism towards a disabling social-political environment. Most probably, the reaction of these parents when faced with the disability of their children is influenced by emotional, cognitive, and relational factors, as it is evident from the greater emotional participation in their focus groups. They daily experience their children's discrimination and realize that, while they regard them as people, their children are considered different in society.

The parallel analysis developed at the 'dimensions of experience' level, allowed us to discover the existence of a relationship among disability models and the modalities of expression of the participants. Parents, for example, seem to support some assumptions of the biopsychosocial model, but only at a level of 'opinions', while when they refer to 'behaviours' those assumptions disappear and the social model reappears. In almost all the groups, the medical model is often expressed with 'behaviours', along with emotions like 'anguish' and 'sadness'. Finally, the social model is expressed through 'opinions', 'behaviours', and emotions such as 'anger' and 'disgust'.

\section{QUANTITATIVE ANALYSIS PROCEDURES AND RESULTS}

\section{Quantitative Analysis Hypothesis}

We performed the analysis to test the following hypothesis: if the qualitative interpretation aiming to assign a disability model (medical, social, or biopsychosocial) to the partici- pants of each focus group according to the majority of the opinions of their components, is true, then we must find a greater number of those codes (attributed to the texts of each focus group) united in the 'family' relative to the model appearing in each focus group.

\section{Quantitative Analysis by Means of Chi-Square Test}

The quantitative analysis was carried out on the 17 roleand region-homogeneous focus groups. The frequencies of 36 codes, of 3 "code families" categories, of 3 disability models, and of 5 personal experience dimensions, obtained with Atlas.ti, were analysed using the Chi-square $\left(\chi^{2}\right)$ with $k$ $l$ degree of freedom (where $k$ is the number of rolehomogeneous groups) in order to test the hypothesis that the observed frequencies do not differ from their expected values in each focus group. About the disability models and the personal experience dimensions, we summed the occurrences of the codes relative to the same disability model and each occurrence of the codes relative to the same personal experience dimension. Then, we calculated the significance of the differences within and among the groups.

\section{Results of Quantitative Analysis Using $\chi^{2}$ Distribution}

A first analysis was carried out to check the differences among the 17 groups according to the 3 code families (environment, disability as personal condition, continuum between ability and disability) and the remaining 15 codes not included in the above 3 categories.

Table 4. Distribution of Observed and Expected Frequencies (Among and Within) of the 3 'Code Families' in the Groups, and Relative Significance Scores, Applying the $\chi^{2}$ Test $(\mathbf{p}<.05)$

\begin{tabular}{|c|c|c|c|c|c|c|c|c|c|c|c|c|}
\hline & & & \multicolumn{9}{|c|}{ Code Families } & \multirow{4}{*}{ Sig. } \\
\hline & & & \multicolumn{3}{|c|}{ Environment } & \multicolumn{3}{|c|}{$\begin{array}{c}\text { Disability as Personal } \\
\text { Condition }\end{array}$} & \multicolumn{3}{|c|}{ Ability/Disability Continuum } & \\
\hline \multirow{2}{*}{\multicolumn{3}{|c|}{$\begin{array}{c}\text { Focus Group } \\
\text { [FG] }\end{array}$}} & \multirow{2}{*}{$\begin{array}{l}\text { Observed } \\
\text { Value }\end{array}$} & \multicolumn{2}{|c|}{ Expected Value } & \multirow{2}{*}{$\begin{array}{c}\text { Observed } \\
\text { Value }\end{array}$} & \multicolumn{2}{|c|}{ Expected Value } & \multirow{2}{*}{$\begin{array}{l}\text { Observed } \\
\text { Value }\end{array}$} & \multicolumn{2}{|c|}{ Expected Value } & \\
\hline & & & & Among & Within & & Among & Within & & Among & Within & \\
\hline \multirow{6}{*}{ Parents of disabled students } & \multirow{4}{*}{ Lazio } & FG1 & 14 & 19.35 & 7,33 & 3 & 7.76 & 7,33 & 5 & 7.00 & 7,33 & 0.009 \\
\hline & & FG13 & 34 & 19.35 & 14,67 & 2 & 7.76 & 14,67 & 8 & 7.00 & 14,67 & 0.005 \\
\hline & & FG14 & 26 & 19.35 & 12,67 & 5 & 7.76 & 12,67 & 7 & 7.00 & 12,67 & 0.005 \\
\hline & & FG15 & 19 & 19.35 & 8,67 & 6 & 7.76 & 8,67 & 1 & 7.00 & 8,67 & 0.005 \\
\hline & Apulia & FG7 & 29 & 19.35 & 17,33 & 8 & 7.76 & 17,33 & 15 & 7.00 & 17,33 & 0.005 \\
\hline & Umbria & FG17 & 18 & 19.35 & 9,00 & 3 & 7.76 & 9,00 & 6 & 7.00 & 9,00 & 0.005 \\
\hline Parents of non-disabled students & Lazio & FG2 & 17 & 19.35 & 12,67 & 14 & 7.76 & 12,67 & 7 & 7.00 & 12,67 & 0.125 \\
\hline \multirow{3}{*}{ Non-specialized teachers } & Lazio & FG3 & 15 & 19.35 & 8,67 & 5 & 7.76 & 8,67 & 6 & 7.00 & 8,67 & 0.030 \\
\hline & Molise & FG8 & 14 & 19.35 & 10,67 & 14 & 7.76 & 10,67 & 4 & 7.00 & 10,67 & 0.005 \\
\hline & Umbria & FG9 & 31 & 19.35 & 17,67 & 16 & 7.76 & 17,67 & 6 & 7.00 & 17,67 & 0.005 \\
\hline \multirow{3}{*}{ Specialized teachers } & Lazio & FG4 & 7 & 19.35 & 6,00 & 8 & 7.76 & 6,00 & 3 & 7.00 & 6,00 & 0.311 \\
\hline & Molise & FG10 & 21 & 19.35 & 10,00 & 7 & 7.76 & 10,00 & 2 & 7.00 & 10,00 & 0.005 \\
\hline & Umbria & FG11 & 25 & 19.35 & 12,67 & 6 & 7.76 & 12,67 & 7 & 7.00 & 12,67 & 0.005 \\
\hline \multirow{3}{*}{ Social-health workers } & Apulia & FG5 & 23 & 19.35 & 18,33 & 15 & 7.76 & 18,33 & 17 & 7.00 & 18,33 & 0.389 \\
\hline & \multirow{2}{*}{ Umbria } & FG12 & 11 & 19.35 & 8,00 & 6 & 7.76 & 8,00 & 7 & 7.00 & 8,00 & 0.417 \\
\hline & & FG16 & 6 & 19.35 & 8,33 & 10 & 7.76 & 8,33 & 9 & 7.00 & 8,33 & 0.595 \\
\hline Special needs educators & Molise & FG6 & 19 & 19.35 & 10,67 & 4 & 7.76 & 10,67 & 9 & 7.00 & 10,67 & 0.005 \\
\hline \multicolumn{3}{|l|}{ Sig. } & \multicolumn{2}{|c|}{0.005} & & \multicolumn{2}{|c|}{0.005} & & \multicolumn{2}{|c|}{0.005} & & \\
\hline
\end{tabular}


All the 3 code families showed significant results among the groups (Table 4). The distribution of the code families within each role- and region-homogeneous group resulted significant in almost all the groups, except in 5 of them: one of parents of non disabled students of Lazio, one of specialized teachers of Lazio, and three of social-health workers of Apulia and Umbria.

Table 4 shows the frequency distributions of the 3 code families in the groups.

Only 4 of the remaining 15 codes, not included in the above categories, resulted significantly different among the groups: 'diversity of the disabled', 'tragic vision of disability', 'disability not a synonym of handicap', and 'inclusive interventions' (Table 5). Only 2 of the 4 codes, namely 'diversity of the disabled' and 'tragic vision of disability' (typical of the medical disability model), seem to be a part of the cultural background of all the participants (exception made for only 2 groups, where these codes were never recorded). The significance values in the distribution of the 4 codes within each group seem influenced by the presence (FG7,
FG8, FG9, FG10, FG11, FG12 and FG15) or absence (FG1, FG2, FG3, FG4, FG5, FG6, FG13, FG14, FG16 and FG17) of the codes 'disability not a synonym of handicap' and 'inclusive interventions' (as noted above), rather than by the specific distribution of the values of the 4 codes observed in each group. In fact, the distribution of the observed values for the codes 'diversity of the disabled' and 'tragic vision of disability' does not reach significance for the $\chi^{2}$ test (exception made for FG14).

A subsequent statistical analysis highlighted significant differences among the groups concerning the distribution of 2 out of 3 disability models: the social and the medical ones (Table 6). No significant differences were observed for the biopsychosocial model, equally spread over the groups, divided by role or by region, although it appears with some more frequency in the subjects from Umbria (with an important exception concerning the parents of disabled students in Apulia). In general, significant differences in the distribution of the 3 models appear in all the groups, with the exception of the following: parents of non disabled, specialized teachers from Lazio, social-health workers. This result is congru-

Table 5. Distribution of Observed and Expected Frequencies (Among and Within) of the 4 Codes Found Significant in the Groups and Relative Significance Scores, Applying the $\chi^{2}$ Test $(p<.05)$

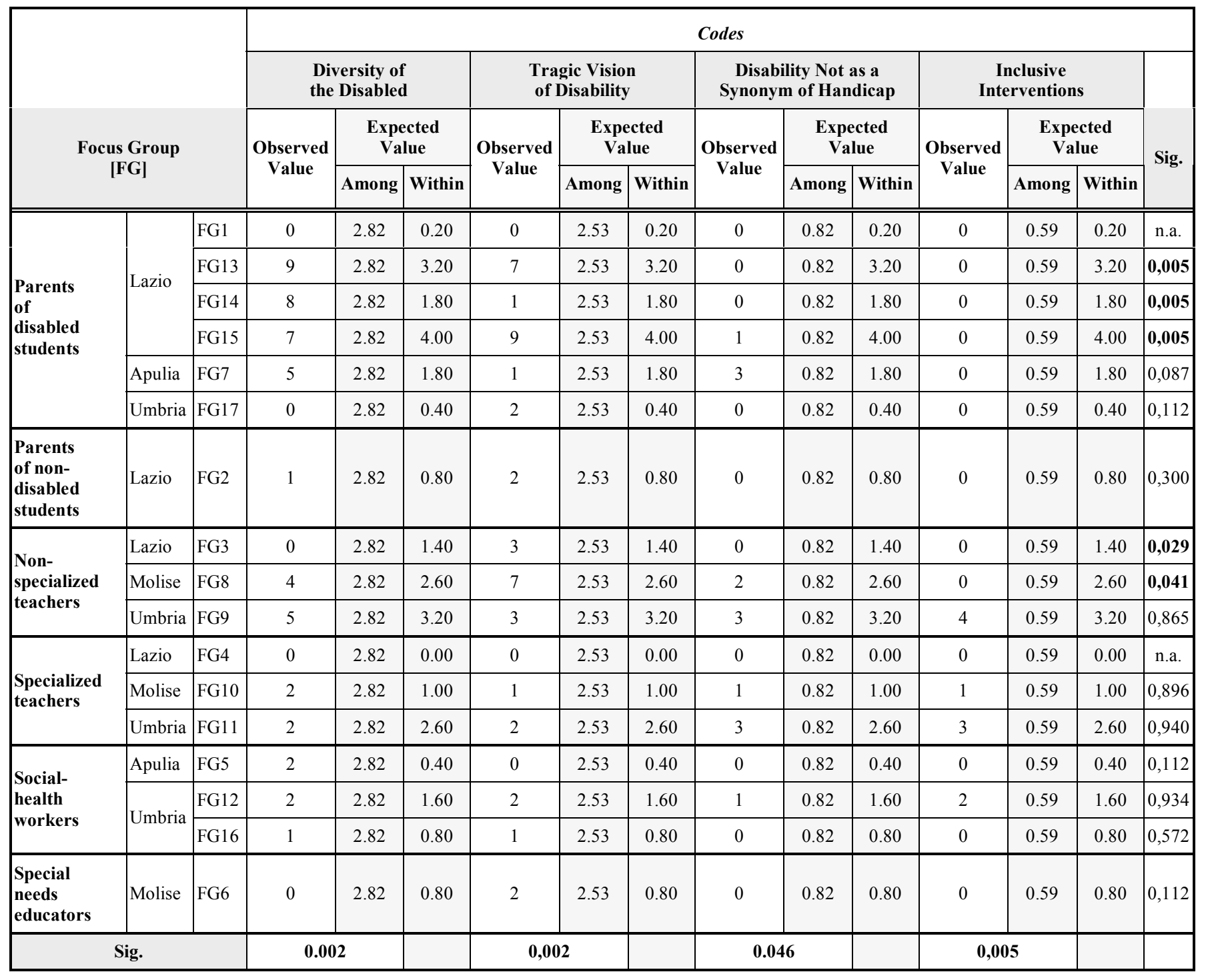


Table 6. Distribution of Observed and Expected Frequencies (Among and Within) of the 3 Disability Models in the Groups and Relative Significance Scores, Applying the $\chi^{2}$ Test $(\mathrm{p}<.05)$

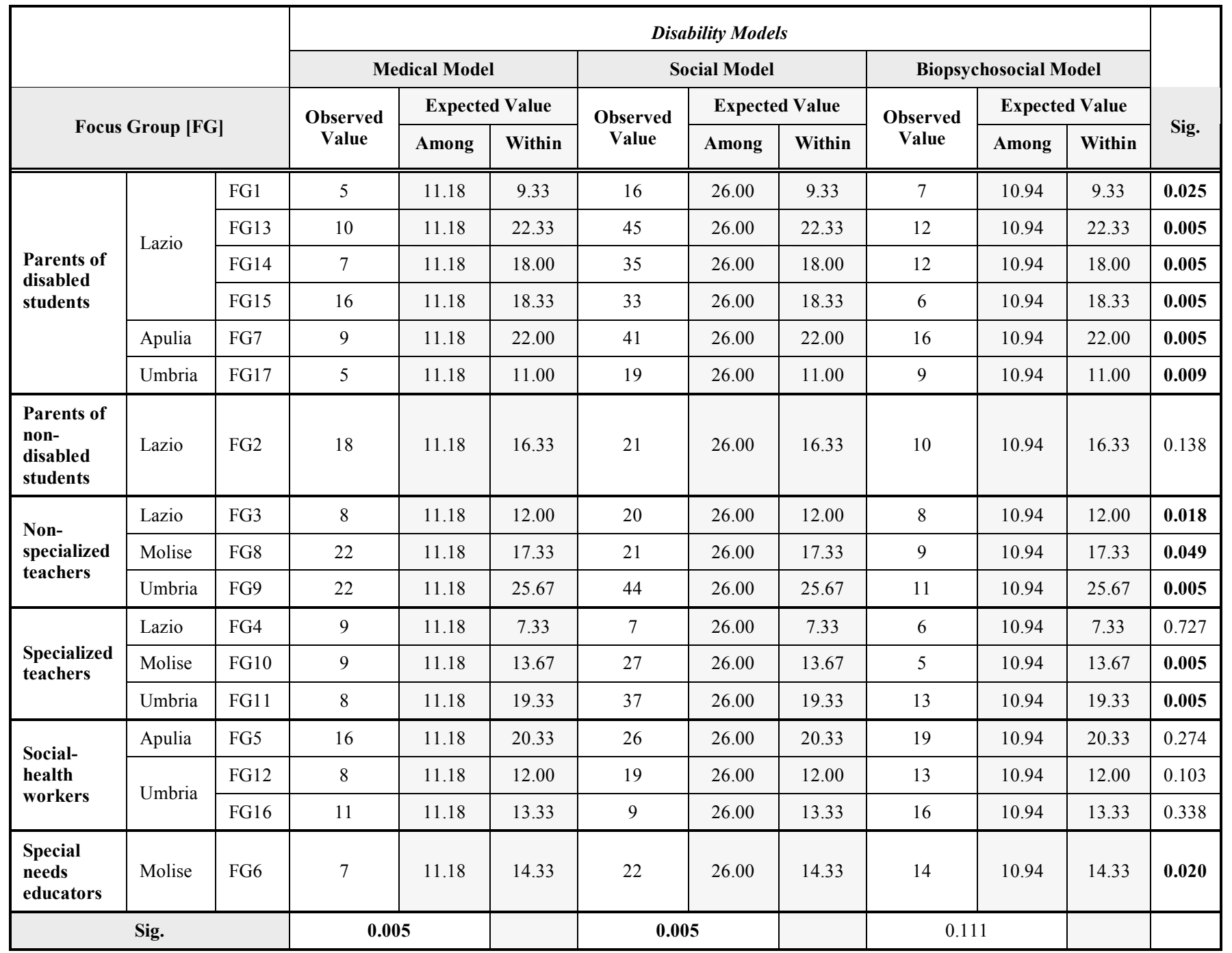

ent with the outcome of the analysis carried out on the 3 code families (Table 4 ).

The distribution of the 5 dimensions concerning personal experience resulted significantly different within all the groups (Table 7). Parents, teachers, social-health workers, and special needs educators express themselves mainly showing opinions and behaviours, while emotions like anger, anguish, sadness, disgust, and joy appear only in parents and non-specialized teachers.

As indicated in Table 7, the analysis concerning the emotions was carried out only on 6 groups homogeneous for educative role. In those groups in which opinions and behaviours showed a prevalence of the social model these dimensions were emotionally expressed as well; in groups in which the biopsychosocial model prevailed, the participants expressed mainly opinions, while in groups with preference for the medical model, the participants expressed both behaviours and opinions. Lastly, the distribution of opinions, behaviours, and emotions, resulted significantly different, while the opposite was true for the distribution of attitudes and myths/stereotypes.

\section{DISCUSSION AND CONCLUSIONS}

The study reached the aim to verify the perspective on disability according to the different educational roles.

The results obtained from the qualitative analysis showed that the horizon of perspectives is much more diversified than the division in medical, social, and biopsychosocial models. Moreover, the qualitative analysis assisted by the software highlighted, in some cases, different perspectives on disability in contrast with the ones that appeared in the manual textual analysis (Table 8).

These differences demonstrate that the bottom-up procedure assisted by Atlas.ti enabled us to notice more different perspectives on disability among the groups and, sometimes, also within the groups themselves. Anyway, we can affirm that the specific role that the participants play in an educational context orients their visions concerning disability.

Hence, from the results we can conclude that:

- The social-health workers and the special needs educators, as interpreted on the basis of the qualitative analysis results, refer more to a transitional model lo- 
Table 7. Distribution of Observed and Expected Frequencies (Among and Within) of the 5 Dimensions of Personal Experience in the Groups and Relative Significance Scores, Applying the $\chi^{2}$ Test $(p<.05)$

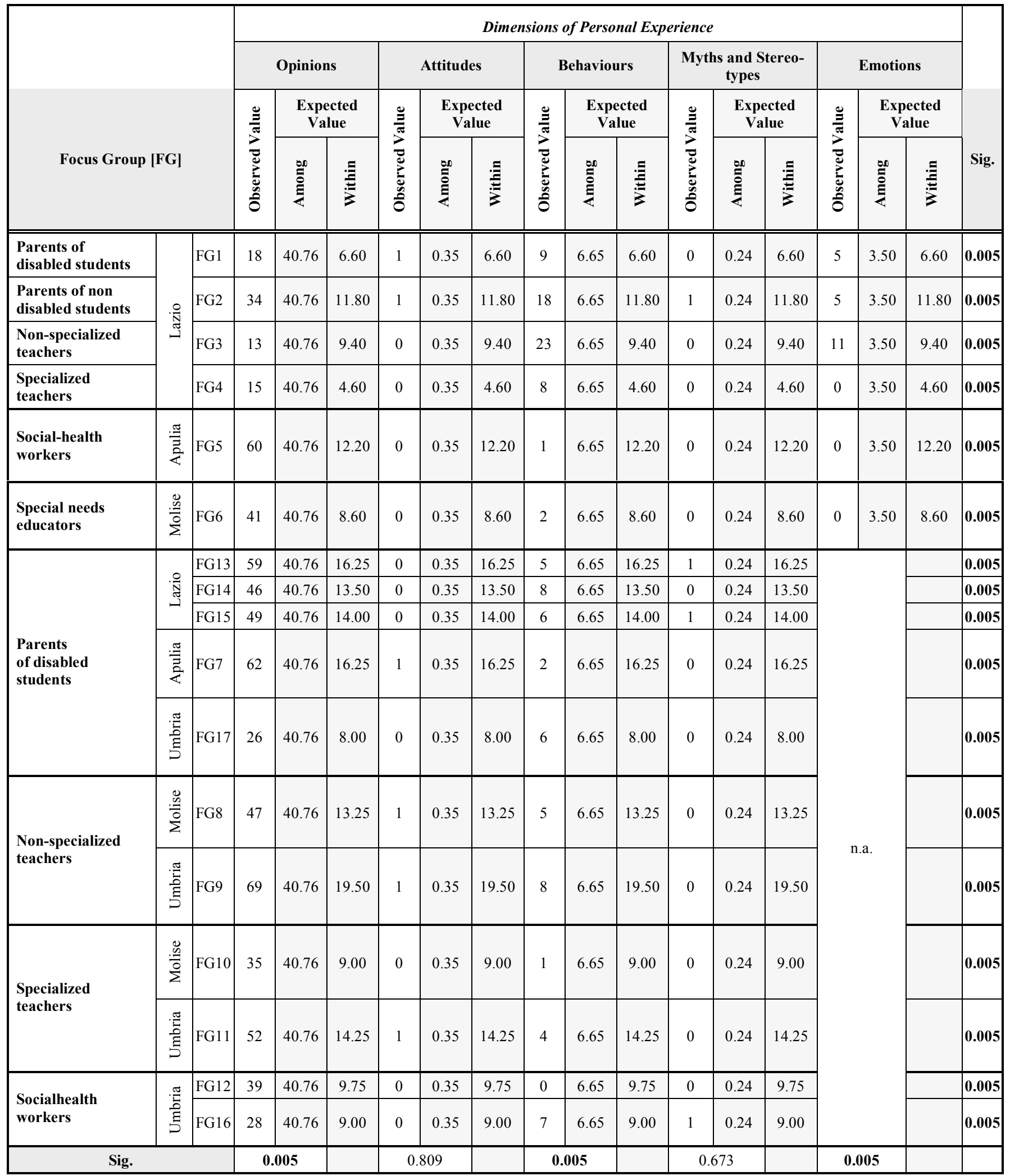

cated in the interplay between the social and the biopsychosocial ones; however, from the software assisted analysis it results that only among the educators there is a significant prevalence of the values con- nected to the social and biopsychosocial models with respect to the medical one;

- The parents of disabled students, the non-specialized teachers, and the majority of the specialized teachers 
are the groups that more adhere decisively to the premises of the social model;

With respect to parents of non disabled students, as interpreted on the basis of the qualitative analysis results and confirmed by the $\chi^{2}$ test, no disability model emerges as prevalent.

Therefore, the qualitative analysis assisted by Atlas.ti mostly confirmed the appearance of a transitional model including aspects of the social and biopsychosocial ones, in addition to some elements of the medical model.

In the quantitative analysis carried out with the $\chi^{2}$ test, the statistical hypotheses were verified. The statistical analysis of the distribution of disability models in the groups confirmed that the attribution of a specific model to each group depends on the greater scores of the codes united in the 'family' referring to the model occurring in each group. The appearance of significant differences in codes' and code families' distributions, considering the different disability models, confirms that there are different visions of disability spread among the groups according to the different educational roles, but also shows that all the participants share common elements with reference to disability. In fact, a certain amount of 'tragedy' and 'diversity' colours the declarations of the participants, independently from their personal way of defining disability. Moreover, the quantitative analysis confirmed the results obtained with the qualitative analysis assisted by Atlas.ti concerning the presence of the medical model, not only among the parents of disabled students, but partially also among the social-health workers. The statistical analysis of the personal experiences' distribution in the groups highlighted an interesting correlation among the foremost disability model in each group and the modalities of expression of the personal experiences of the participants. This would explain even more the presence, within the groups, of different perspectives on disability.

The presence of different models within the groups leads to some additional conclusions:

There is a cultural predisposition for the adhesion to the biopsychosocial model, since the participants have the tendency to define disability in terms of individual functioning, rather than using ability/inability polarities. This would be proved by the fact that the groups more exposed to educational, informative, and formative agents (social-health workers and educators) are also the ones more 'in transit' among the models, differently from the parents of disabled students, whose adhesion to the social model is sharper and less blurred.

- Among the parents of non disabled students, the presence of a perspective on disability partially different compared to the one that parents of disabled students have, let us think over the role played by the experience of disability for the parents.

- The adhesion of the parents of disabled students to the social model, also in the light of the analyses based on transcriptions, appears to be based to the frequent use of the psychological mechanisms of denial: minimizing their children physical problems, opposing resistance to the acknowledgement of the importance of disablements, of the deficits, etc. These denial mechanisms would favour in parents a reduction of the importance of the limitation of individual abilities and an enhancement of the relevance of restrictions in participation to the social life.

- The use of the terms such us 'disability' and 'handicap' as synonyms, differently from the use that both ICIDH and ICF make of them, pushes us to consider the influence that these documents have on Italian culture. We must certainly keep in mind that the term 'handicap' sounds more neutral than 'disability' in Italian, differently than in English where it sounds as negative, and that is the reason why the choice of ICF was to substitute it definitely with the general term 'disability' [5, Annex 1, pp. 187-188]. Moreover, in the Italian legislation about disability the term 'handicap' is used, following the definition provided by ICIDH: certainly this use also has a much stronger social impact in comparison to the ICF, which, proposing the general term 'disability', has not taken into account the meaning that handicap and disability have in Italian and French languages. The fact that among the participants the terms 'disability' and 'handicap' were used as synonyms, and were not hence interpreted as indicating different disability models, could have been a consequence of the fact that the moderators explained that they used the term 'disability' as a comprehensive general term (therefore as a synonym for 'handicap').

Different representations of disability, determined and sustained by different models, probably create diverse emotions and behaviours towards disabled people. Knowing which disability model prevails within a specific group of people may be of crucial importance for planning and implementing adequate projects of intervention and individualized training.

Moreover, the current study allows us to know the real spreading of the biopsychosocial model proposed by WHO $[5,7]$ among educators and parents and verify which steps are still necessary so that this model is universally shared. In fact, biopsychosocial model may provide school and society with more adequate tools to give more complex mental representations of disability, less stereotyped and closer to disabled people's real life as they live everyday rather than based on prejudices and stereotypes.

The scarce diffusion of the biopsychosocial model among the parents highlights the lack of a vision 'opened' to perspective of personal development, of social growth, of improvement of the life quality standards. This suggests a priority: the need to extend the educational instances also to parents and caregivers, in order to promote a more efficient management of personal and environmental resources in facing their children's disability, in the perspective of developing and promoting a new 'culture of diversities'.

As S. Federici and M. Olivetti Belardinelli declare [8], the adoption of the biopsychosocial model, on the field of Cognitive Psychology, offers new perspectives, detaching the experimental paradigms from the prejudice of 'normal' mental functioning. The diverse and numerous ways to operate, also those that could be classified as abnormal and dis- 
Table 8. Comparing Results from the Manual Text Analysis and Qualitative Analysis Assisted by Atlas.Ti as Regards the Frequency of Disability Models in the Groups. The Number Points out the Frequency of the Three Disability Models Codes

\begin{tabular}{|l|c|c|c|c|c|c|}
\hline \multirow{2}{*}{ Roles } & \multicolumn{2}{c|}{ Medical Model } & \multicolumn{2}{c|}{ Social Model } & \multicolumn{2}{c|}{ Biopsychosocial Model } \\
\cline { 2 - 7 } & Manual & Atlas.ti & Manual & Atlas.ti & Manual & Atlas.ti \\
\hline \hline Parents of disabled students & 63 & 52 & $215^{*}$ & $189^{*}$ & $80^{* *}$ & 62 \\
\hline Parents of non disabled students & 18 & 18 & 23 & 21 & 15 & 10 \\
\hline Non-specialized teachers & 45 & $52 * *$ & $71^{*}$ & $85^{*}$ & 43 & 28 \\
\hline Specialized teachers & 22 & 26 & $60^{*}$ & $71^{*}$ & $44^{* *}$ & 24 \\
\hline Special needs educators & 4 & 7 & 12 & $22^{*}$ & $20^{*}$ & 14 \\
\hline Social-health workers & 28 & 35 & $55^{*}$ & 54 & $51^{* *}$ & 48 \\
\hline
\end{tabular}

*Model prevalent describing the opinions for the majority of the group. **model spread in the group even if not descriptive of the opinions of the majority.

abled by some psychophysiology, can be considered as different ways to build reality.

\section{REFERENCES}

[1] Quinn P. Understanding Disability: A Lifespan Approach. Thousand Oaks: Sage 1998.

[2] Rubenfeld P, Schwartz A. Early onset of a disability: Its impact on development and adult outcomes. SCI Psychosocial Process 1996; 9(2-3): 60-3.

[3] Goffman E. Stigma: Notes on the Management of Spoiled Identity. Englewood Cliffs, NJ: Spectrum Book 1963.

[4] Olivetti BM. La costruzione della realtà. Torino, Boringhieri 1973.

[5] World Health Organization. International Classification of Functioning, Disability and Health: ICF. Geneva: World Health Organization 2001.

[6] Bruyere SM, Van Looy SA, Peterson DB. The International Classification of Functioning, Disability and Health: Contemporary Literature Overview. Rehabil Psychol 2005; 50(2): 113-21.

[7] Bickenbach JE, Chatterji S, Badley EM, Üstün TB. Models of disablement, universalism and the international classification of impairments, disabilities and handicaps. Soc Sci Med 1999; 48(9): 1173-87.

[8] Federici S, Olivetti Belardinelli M. Un difficile accordo tra prevenzione e promozione. Psicol Clin Dello Sviluppo 2006; (2): 330-4.

[9] Adams J, Swain J, Clark J. What's so special? Teachers' models and their realisation in practice in segregated schools. Disabil Soc 2000; 15(2): 233-45.

[10] Brett J. The experience of disability from the perspective of parents of children with profound impairment: Is it time for an alternative model of disability? Disabil Soc 2002; 17(7): 825-43.

[11] Jenks EB. Explaining disability: parents' stories of raising children with visual impairments in a sighted world. J Contemp Ethnogr 2005; 34(2): 143-69.

[12] Kelly SE. 'A Different Light': Examining impairment through parent narratives of childhood disability. J Contemp Ethnogr 2005; 34(2): 180-205.

[13] Ong-Dean C. Reconsidering the social location of the medical model: an examination of disability in parenting literature. J Med Humanit 2005; 26(2-3): 141-58.

[14] Asprey A, Nash T. The importance of awareness and communication for the inclusion of young people with life-limiting and lifethreatening conditions in mainstream schools and colleges. $\mathrm{Br} \mathrm{J}$ Spec Educ 2006; 33(1): 10-8.
[15] Heiman GW. Understanding Research Methods and Statistics: An Integrated Introduction for Psychology. New York City: Houghton Mifflin College Div 1997.

[16] Warr DJ. 'It was fun... but we don't usually talk about these things': Analyzing Sociable Interaction in Focus Groups. Qual Inq 2005; 11(2): 200-25.

[17] Wilkinson S. Focus Groups in Health Research. Exploring the Meanings of Health and Illness. J Health Psychol 1998; 3(3): 32948.

[18] Linhorst DM. A review of the use and potential of focus groups in social work research. Qual Soc Work 2002; 1(2): 208-28.

[19] Chiu LF. Transformational potential of focus group practice in participatory action research. Action Res 2003; 1(2): 165-83.

[20] Morgan DL. Focus groups as qualitative research. London: Sage 1988.

[21] Zammuner VL. I focus group. Bologna: Il Mulino 2003.

[22] Krueger RA. Focus groups: A practical guide for applied research. London: Sage 1988.

[23] World Health Organization. International Classification of Impairments, Disabilities, and Handicaps. A Manual of classification relating to the consequences of disease. Geneva: World Health Organization 1980.

[24] Strauss AL, Corbin J. Basics of qualitative research: Grounded theory procedures and techniques. London: Sage 1990.

[25] Fielding NG, Lee RM. Computer analysis and qualitative research. London: Sage 1998.

[26] Lee RM, Fielding NG. Computing for qualitative research: Options, problems and potential. In: Fielding NG, Lee RM, Eds. Using computers in qualitative research. London: Sage 1991.

[27] Coffey A, Holbrook B, Atkinson P. Qualitative data analysis: Technologies and representations. Sociological Research Online 1996; 1(1). Retrieved 2007, Jan 10 from website: http://www.socre sonline.org.uk/1/1/4.html\#top.

[28] Muhr T. Atlas.ti - A prototype for the support of text interpretation. Qual Sociol 1991; 14(4): 349-71.

[29] Hughes B, Paterson K. The social model of disability and the disappearing body: towards a sociology of impairment. Disabil Soc 1997; 12(3): 325-40.

[30] UPIAS, The Disability Alliance. Fundamental Principles of Disability. London: Union of the Physically Impaired Against Segregation 1976.

[31] Strauss AL. Qualitative analysis for social scientists. New York: Cambridge University Press 1987. 